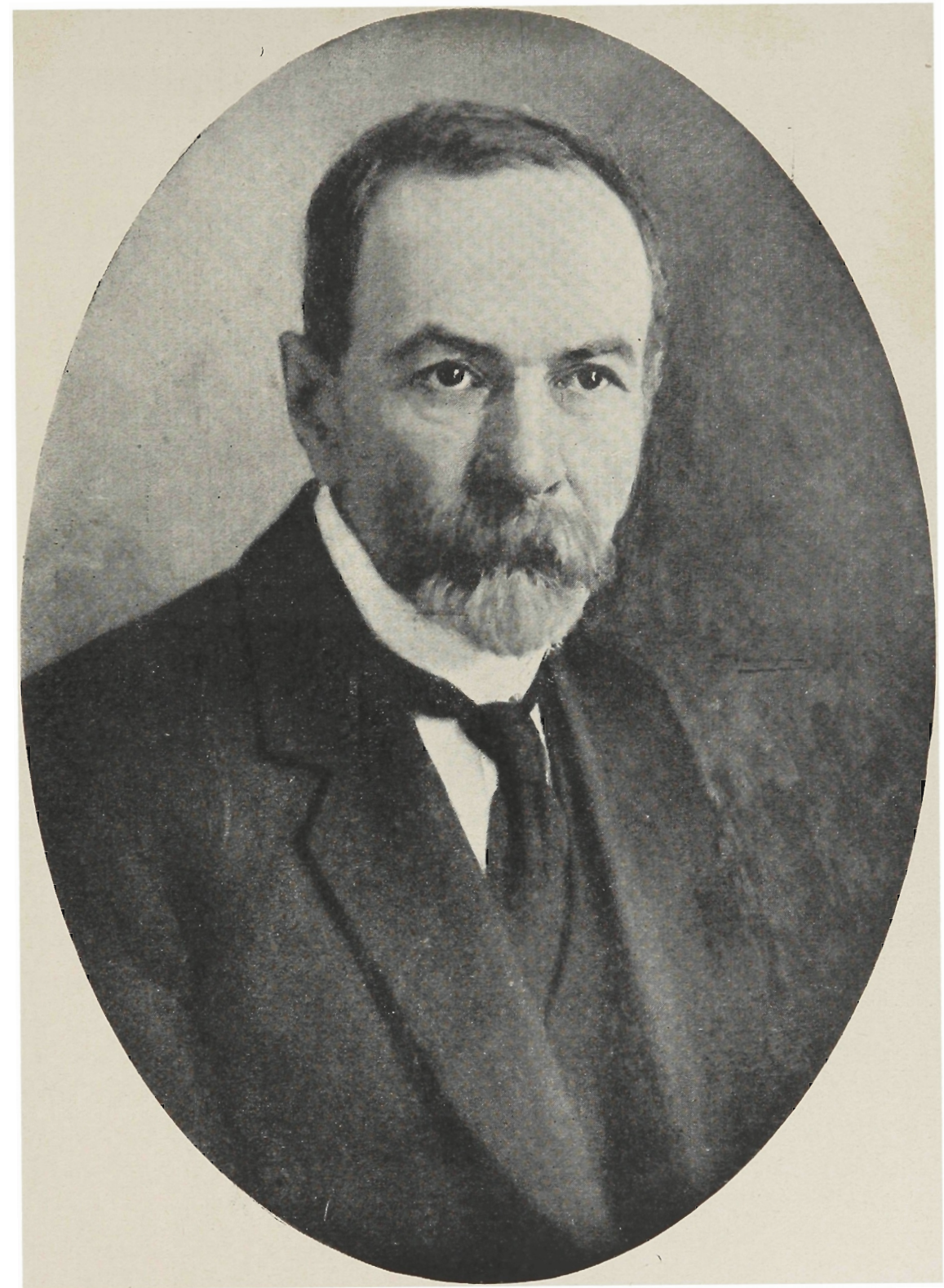

DR. JULIO JOAQUIM GONÇALVES MAIA 


\section{Julio Joaquim Gonçalves Maia}

\section{Waldemar Ferreíra}

1. Recordo, sempre emocionado, o dia festivo da minha colação de grau de bacharel em ciencias e letras, no Ginásio Nogueira da Gama, que Lamartine Delamare, o velho educador brasileiro, mantinha em Jacaréi e ainda hoje dirige em Guaratinguetá. Primeiro ginásio equiparado do Estado de São Paulo, foi dos ultimos, no entanto, a conferir o grau de ensino secundario, tamanha a ética do seu nobre fundador. A minha turma foi a primeira a bacharelar-se. Meia duzia. Adalberto Leme Ferreira, Alfredo Pimenta de Padua, João Otavio Neves, Jaime Pimenta de Padua, Joaquim Vitor de Souza Meireles Neto, Waldemar Martins Ferreira. Paraninfou-a luiz Nunes Ferreira Filho, professor de linguas áquele tempo e, mais tarde, professor da Faculdade de Direito do Rio de Janeiro. Presidiu a solenidade Domingos Rubião Alves Meira, o já notavel clinico que viria a ser professor dos mais insignes da Faculdade de Medicina da Universidade de São Paulo, como delegado fiscal do governo federal. Desvanecido, depois do meu discurso de orador da turma, de suas mãos recebi o meu diploma de bacharel, a que uma larga fita verde amarela, entrelaçada á margem do pergaminho, com as duas pontas presas, num estojo de prata, por um carimbo em pingo de lacre, dava o colorido dum documento nacional.

Foi isso aos 20 de fevereiro de 1904.

Meu Pai, a quem passei o diploma, que acabara de receber e ia abrir-me as portas dos cursos superiores, acolheu-o justamente comovido, como presente raro e hon- 
rosissimo para um homem pobre, que via coroado de exito fase das de maior rudeza de sua vida cheia de trabalhos.

De regresso ao nosso torrão natal, tomou-se, como era natural, de cuidados pelo meu diploma. Ofereceu-se-lhe, e o of erecimento foi aceito prazenteiramente, para tirar dele a publica fórma havida como necessaria para a minha entrada no curso superior a que me destinava, um dos tabeliães conterraneos, Francisco da Silveira Guimarães, depois transferido para uma das escrivanías orfanologicas desta comarca. Enquadrado, a seguir, em larga e vistosa moldura, passou, para gaudio da familia, a ornamentar uma das paredes da modestissima sala de visitas de nossa boa casa provinciana.

Março era o mês das matriculas na Faculdade de Direito de São Paulo. Estavam em vesperas de findar-se, quando tratei da minha. Redigido o meu requerimento, ao pé do qual José Luis de Almeida Nogueira, que seria meu professor de economia politica, atestou minha identidade, juntei os documentos exigidos pelos regulamentos. Receioso de tudo e de todos, como o mais timorato dos calouros, dirigi-me para o velho mosteiro do largo de São Francisco, cuja demolição eu haveria, duas décadas depois, de ordenar e efetuar-se para a construção do grande e monumental palacio, que no mesmo chão se ergueu. Ao transpôr a porta alta e larga, encimada pela placa com o nome glorioso de Alvares de Azevedo, achei-me no átrio, tendo á frente a portada das arcadas e as duas escadas marmoreas, que a ladeavam, e iam ter ao primeiro andar. Subi a da direita, que dava numa porta aberta. Entrei. Sala quasi monacal. No canto direito, um terno de mobilia preta, de palhinha, austriaca. Grande relogio de armario antigo. Dando costas para a janela, trabalhava em sua mêsa, cheia de papeis, o secretário, de imensa popularidade, cuja aspereza era notoria. Inumeras pessôas, de pé, aguardavam a vez de ser atendidos. Esperei que chegasse a minha, examinando o novo ambiente, que se me apresentava. Estava meio em êxtase, quando o secretário me perguntou o que queria. 
- Veiu matricular-se? A esta hora? Porque não chegou antes?

Não respondi, meio aturdido. Atirei-lhe ás mãos, maquinalmente, o meu requerimento. O secretário - era Juuso MAIA - a fitar-me, desenrolou-o, enrolando-o em seguida em sentido oposto, afim de distender o papel. Leu-o. Releu-o. E inquiriu-me:

- Como se chama 0 senhor é o proprio Waldemar Martins Ferreira?

Sem esperar a resposta, entrou a examinar os documentos. Deu com a publica fórma de meu diploma de bacharel em ciencias e letras. Leu-a demoradamente, sublinhando a lapis azul um de seus topicos. Mas não se conteve:

- Não! Não está certo! O senhor não está com os seus documentos em ordem! Onde está o seu diploma? Não o trouxe? Guardou-o como reliquia?

- Aí está, tartamudei, a publica fórma.

- Ora, a publica fórma! Pois o senhor não sabe que publica fórma, por si só, sem ser conferida, não vale nada? Nunca leu o regul. n. 737?

$\mathrm{Eu}$, que jamais tinha ouvido falar nesse regulamento, e confiava muito mais na sabença do tabelião de minha comarca, fiquei tonto. Então a publica fórma não valía nada?!.

— De onde é? De Bragança? Pois se lá deixou o selı diploma, mande busca-lo. E com urgencia! Para não perder a sua matricula. Terminado o prazo, não se matriculará! Deixe o seu requerimento e traga-me logo o seu diploma. Não perca tempo!

Desci a escada curva aos saltos. Corri ao telegrafo, mais morto do que vivo, meio confuso. Com que então a publica fórma, com o sinal publico do tabelião, por ele tirada e conferida, devidamente selada, não valía nada!.

Deu-me Julio MaIA a minha primeira lição de direito, logo de entrada. Manuseei, quando pude, o regul. n. 737, de 25 de novembro de 1850 , e tirei a prova dos nove. O homem tinha razão. 
Meu Pai, sem compreender bem o meu telegrama, mandou retirar das molduras, em que, com tanto carinho, o fizera enquadrar, o meu diploma, e imediatamente mo enviou. Aos 26 de março de 1904, apresentado ele, determinou Julio Maia a minha matricula no primeiro ano da Faculdade de Direito de São Paulo, como vigesimo quinto duma lista encimada, em primeiro lugar, pelo nome de Pedro Antonio de Oliveira Ribeiro Sobrinho, e que veiu a encerrar-se com o de Jose' Antonio Nogueira.

Cento e cincoenta e cinco calouros!

2. Nasceu Julio Gonçalves Maia em Iguape, velha cidade litoranea paulista, a 1 de outubro de 1857. Pôs-lhe os santos oleos, em 1 de janeiro de 1858, na Igreja Matriz do Bom Jesus de Iguape, o seu Vigario Antonio Carnerro dA Silva Braga. O pai, Joaguim Gonçalves Maia, era português. A mãi, D. Maria Angelica Xavier Maia, brasileira, neta do sargento-mór Bartolomeu da Costa Almeida da Cruz

Naquela cidade estudou Julio Gonçalves Maia as primeiras letras, na escola de Francisco Antonio Pereira. Empregou-se, muito jovem, no comercio, no Rio de Janeiro, seguindo, provavelmente, a inspiração paterna. Mas logo mudou de rumo. Veiu para São Paulo, estudando, no Seminario Episcopal, os preparatorios, de 1874 a 1877. Aluno do Curso Anexo á Faculdade de Direito, teve sua primeira aprovação, em português, a 1 de dezembro de 1877. O seu ultimo exame foi o de retorica e poetica, em 9 de fevereiro de 1880.

Habilitado, matriculou-se no primeiro ano da Faculdade de Direito em 2 de março daquele ano, tendo como companheiros de turma Edmundo Muniz Barreto, Godofredo Cunha, Sebastião de lacerda, Carlos Augusto de Oliveira Figueiredo, Gastão Mesquita, Jose' Maria Bourroul, Germano Hasslocker Filho, Padua Sales, antonio Lobo, Olavo Egidio, Gastão da Cunha, Eduardo Cunha Canto, Sabino Barroso Junior, Adolfo Correia Dias, Possidonió da Cunha Junior, Augusto Freire da Silva Junior, Pedro de Toledo, Jose' Pereira de Queiroz, Ludgero Coelho, Eugenro Egas, Pedro Ta- 
vares Filho, Jose' de Campos Novais e outros, nomes prestigiosos na magistratura, na politica, na advocacia, nas letras, na diplomacia.

Ao matricular-se, requereu Julio Gonçalves Maia ao diretor licença para assinar-se, e assinou, Julıo JoAQuim GoNgaldes MaIA. Quiz ligar ao seu o prenome paterno, numa tocante homenagem filial. Com este nome recebeu ele o grau de bacharel formado em direito em 5 de novembro de 1884.

3. Iniciando-se na vida pratica, Julio MaIA, como se chamou, teve a sua primeira investidura num cargo do Ministerio Publico: o de curador de heranças jacente, para o qual foi levado por Francisco Antonio de Sousa Queiroz, vice-presidente da provincia. Foi isso em fevereiro de 1885, e por tempo muito curto. Voltou logo a ocupar cargo administrativo na Faculdade de Direito, como ele proprio o disse em palavras dignas de releitura:

"Apenas bacharel formado por este mesmo instituto, a 5 de novembro de 1884, cinco mêses depois de receber o respetivo grau, para aqui voltei trazido pela benevolencia do então diretor, o Conselheiro Dr. Andre' Augusto de Padua FleuRY, a ser um dos seus auxiliares.

"Nomeado oficial da secretaria por portaria do Governo Imperial, de 21 de abril de 1885, esse ato emanado do partido liberal, então no poder, foi surpresa para mim, pois eu era militante no partido conservador, na facção chefiada pelo emerito jurisconsulto e notavel advogado Dr. JoÃo Mendes DE Almeida, a cujo conselho aceitei o lugar, no qual tomei posse a 1 de junho seguinte, entrando, desde então, em exercio.

"No dominio da Republica, com a reforma do Ensino Juridico, constante do decreto n. 1.232-F, de 1 de janeiro de 1891 , fui nomeado por decreto do Governo, de 21 de maio desse mesmo ano, para o cargo de sub-secretario desta Faculdade, tendo tomado posse e entrado no exercicio do cargo, a 6 de abril seguinte, exercendo tambem então ex-vi do disposto no 
art. 455 do citado decreto n. 1.232-F, o cargo de secretario do então Curso Anexo á Faculdade, o qual foi reorganizado sob novas bases pela referida reforma $\left(^{1}\right)$.

"Devo essa nomeação á benignidade do Conselheiro Dr. Carlos Leoncio de Carvalho, que foi lente e diretor desta Faculdade.

"Em 1903, quando Presidente da Republica o Conselheiro Dr. Francisco de Paula Rodrigues Alves, eminente paulista, fui nomeado por decreto de 6 de julho, para o cargo de secretario, na vaga verificada pela aposentadoria do Dr. ANDrE' Dias de Aguiar, tendo tomado posse e entrado no exercicio desse cargo, a 9 desse mesmo mês"

Transferida, pelo decr. n. 24.102, de 10 de abril de 1934, afim de ser incorporada á Universidade de São Paulo, a Faculdade de Direito ao Estado de São Paulo, Julio Mara teve nova nomeação de secretario, por decreto estadual de 16 de maio de 1934.

Aposentado compulsoriamente, pelo presidente da Republica, por decreto de 1 de outubro de 1934, na conformidade do art. 170, n. 3, da Constituição naquele ano promulgada, por ter atingido a idade de 68 anos, tinha Julio MaIA servido a Faculdade de Direito de São Paulo quasi um cincoentenario.

Quem, por tanto tempo, a secretariou com solicitude, inteligencia e amor pelas tradições do velho curso juridico, tem a sua vida entremeiada com a do notavel estabelecimento de ensino juridico, que lhe deve, verdade se diga, bôa parte do seu alto renome e do seu imenso prestigio.

4. Secretario do Curso Anexo, secretario da Faculdade de Direito, atendendo, diaria e infatigavelmente, a cincoenta gerações de moços, Julıo MaIA deixou um nome inesquecivel

1. Houve da parte de Julio Maia, engano de datas, neste trecho de discurso. A sua memoria, sempre fiel e pronta, o traiu. Nomeou-o oficial interino a portaria de 1 de junho de 1885 , e não de 21 de abril do mesmo ano. Assinou-a Meira de Vasconcellos. O decrete, que o nomeou sub-secretario, não foi de 21 de maio, mas de 21 de março de 1891, referendado por João Barbar.ro. A menos, o que é mais provavel, que não houvesse ele revisto o seu discurso, publicado no vol. 30, de 1934, desta mesma revista, pag. 784 . 


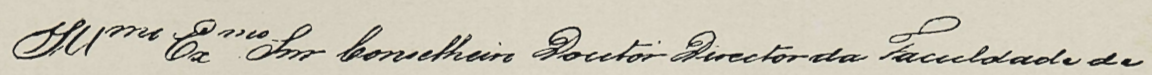
Qusturale-k.

\section{Pircite de tar Sache}

A. Paslo, 150 .

vores rat880.

Hotta.
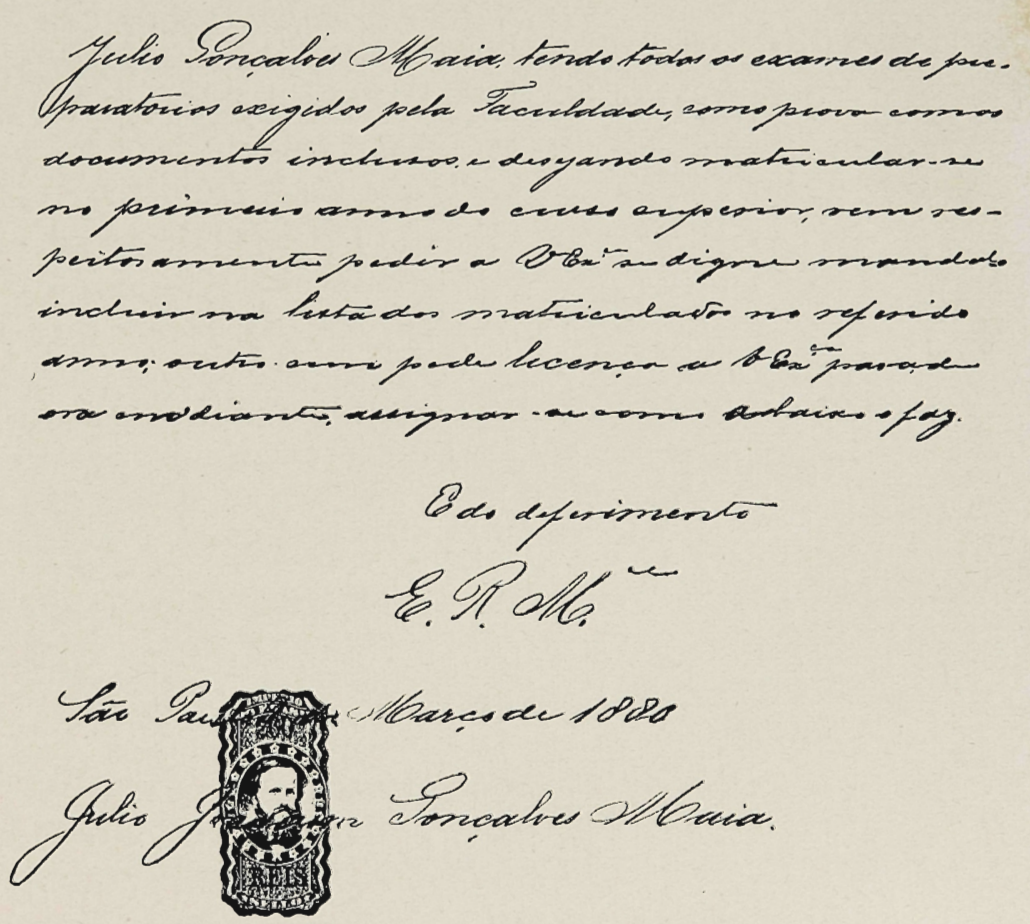

O requerimento de matricula de Julio Maia 
de quantos tiveram de acercar-se dele para inscrever-se em exames ou matricular-se nos dois cursos, o secundario e o superior. Precisou, portanto, de revestir-se de grande fibra para manter-se, como sempre aconteceu, no exercicio de suas funções, respeitado e estimado por todos. Zeloso de seus deveres, foi muito exigente no cumprimento das leis e regulamentos. Não dispensava nada. Nem formalidades. Nem selos. Nem taxas. Como fiscal das leis tributarias, estava sempre atento na defesa do erario publico. Deu isso ensejo a que, já no fim de sua carreira, parodiando o celebre soneto com que Martins Fontes versejou o celebre topico da oração de Alcantara Machado, ao ser recebido na Academia Brasileira, um academico este escrevesse, e que larga popularidade alcançou:

\section{TODOS CANTAM SUAS COISAS}

(Dedicado ao grande Secretario

Dr. Julio Maia)

Sou secretario ha 400 anos

Imortal, indomavel, milenario,

Nas brumas do periodo quaternario

Eu era o mais antigo dos humanos.

Tenho orgulho dos moços paulistanos

Tenho a paixão de ser $O$ Secretario!

Quero morrer ouvindo em meu Calvario

Os discursos sem fim dos veteranos.

Das estampilhas para as estampilhas

Tenho vivido. Considero-as filhas

Do Franciscano casarão que é nosso

Com elas sonho n'um perpetuo enlevo, $E$ se não posso cobra-las quanto devo Quero ao menos lambê-las quanto posso.

$6-6-33$. 
Ao despedir-se da Faculdade de Direito e recebendo as homenagens da Congregação, ao encerrar-se o ano letivo de 1934 e ao inaugurar-se a sala do novo edificio, que recebeu o nome de João Mendes Junior, fez Julio Maia breve relato de sua vida, proferindo estas palavras:

"Eis ai, meus senhores e minhas senhoras, a descrição singela e sem estilo da vida de quasi 50 anos de um funcionario publico, e não de um secretario de 400 anos, como disse, no seu bom humor, um jovem quinto anista formado no começo deste ano, quasi toda ela passada debaixo dessas grossas paredes, feitas de taipas de pilão, deste magestoso edificio, que é a tradicional Faculdade de Direito de São Paulo, o qual, se outra cousa mais proveitosa aqui não fez, ao menos empregou o seu tempo mandando corrigir os erros ortograficos e de sintaxe, colocar as estampilhas, que faltavam, repelindo, com leve admoestação, as não adequadas, e providenciando com animo e prudencia sobre assunto de somenos importancia, pelo que era tido e havido como exigente e ranzinza, mas, não obstante, se esforçou em manter a lei, a ordem e a disciplina e soube captar a simpatia dos lentes, da classe academica e dos seus auxiliares, os quais, por varias vezes, lhe deram justos motivos de jubilo e de grande apreço, amenizando-lhe assim a sua ardua tarefa"

5. Teria sido, realmente, ranzinza e exigente o antigo e saudoso secretario da Faculdade de Direito? Deu-se, ele mesmo, estes qualificativos, para repelir o golpe ferino do antigo aluno, que ele houve como de bom humor. Exigente, efetivamente, foi. Conhecedor das leis e regulamentos do ensino, de que se constituiu repositorio vivo e arguto, não transigiu nunca com eles. A lei era lei. Havia de ser cumprida tão inteiramente como nela se continha e declarava. Exigente, ainda, quanto á correção de linguagem dos requerimentos, que lhe eram apresentados, principalmente pelos estudantes de direito. A estes, ele não perdoava "os erros ortograficos e de sintaxe". Chegou a mandar preparar, nos ultimos tempos, do quasi analfabetismo 
juvenil, formulas de requerimentos, que eram preenchidas, afim de evitar a sua "leve admoestação"

E ranzinza, te-lo-ia sido?

Aureliano Amaral, subsecretario, que ao lado dele e com ele trabalhou por longo tempo, dele disse: "traz sempre a cara intencionalmente amarrada, para que não esteja continuamente a extravasar toda a bondade, que lhe vai lá por dentro" $\left({ }^{2}\right)$. Bem o compreendeu e definiu. A aspereza de Julio Maia foi, a principio, intencional e, depois, se lhe tornou habitual. Ele a adotou, pura e simplesmente, como arma de defesa. Se um lema se tivesse proposto, esse seria muito simples: negar por principio, conceder por sistema. Antes que o bicho, o tigre, o calouro ou, mesmo, o veterano, lhe manifestasse sua pretenção, ele, por gesto $\mathrm{e}$ por palavra, lhe dizia que não. Negava por principio. Negava instintivamente. Negava desde logo, preliminarmente. Mas ouvia o que dele se acercava. Ouvia-o, reprimindo-o. Ouvia-o, entrecortando a exposição de advertencias, mas tudo com certa suavidade, com uma tonalidade de ternura e de carinho, que era só dele. Por fim, o que era possivel fazer, fazia-se. Não foram poucos os que, em aperturas, ouviram dele o conselho apropriado e sugerida a medida necessaria, para que não perdesse a matricula ou a inscrição no exame.

Tendo deixado para os ultimos dias a minha matricula no segundo ano, subita enfermidade, resultante de uma infecção de aroeira, me impediu que deixasse o sitio, em que me encontrava, a tempo de efetua-la. Procurei Julio Mara no dia seguinte ao do encerramento do prazo da lei. Negou-ma. Não podia abrir mau precedente. O prazo estava terminado e as matriculas encerradas desde a vespera. Sugeriu-me, no entanto, matricula como ouvinte, então permitida, e, por fim, citou-me um aviso, que me poderia ser util.

- Porque não telegrafa ao ministro da Justiça, invocando-o e pedindo-lhe que autorize sua matricula?

2. SPENCER VAMPRE, Memorias para a Historia da Academia de São Paulo, vol. 2, pag. 653. 
Aceita a sugestão, dias depois a ordenava J. J. SEAbra, ministro da Justiça de então e que viria a ser meu companheiro de luta politica e colega na Camara dos Deputados, na derradeira legislatura de 1935 a 1937.

Não ha, em verdade, quem tenha passado pela Faculdade de Direito de São Paulo, nestes ultimos cincoenta anos, e não guarde de Julio MaIa um caso ou circunstancia, em que ele lhe não houvesse demonstrado, por fato, que a sua rudeza era só aparencia.

Contou-me, ha dias, o Professor Mario Masagão que, no dia do encerramento da inscrição ao concurso de direito comercial, em 1933, e quasi á hora marcada, para isso, tinham chegado á secretaría os então candidatos e hoje professores Honorio Monteiro e Soares de Faria. Retardara o candidato, e tambem hoje professor ERnesto Leme. Notando que estava a bater a hora e este não aparecia, mas não desejando perdesse ele a inscrição, Julıo MaIA mal ocultou a sua impaciencia. Levantou-se. Foi á janela, que dava para o largo de São Francisco. Nada. Não vinha o candidato. Subitamente, consultando o seu relogio de bolso, mandou que o continuo, que se achava na sala, chamasse o porteiro. Apareceu o Pedrão, o bom, o querido Pedro Dias DE Silva, ha pouco falecido. Inquiriu-o o secretario sobre as horas marcadas no relogio da Faculdade de Direito. E ordenou:

- Acerte o relogio! Não viu que ele está adiantado dez minutos?

Não tardou, porém, que o candidato retardatario aparecesse, apressadamente, trazendo os volumes de sua dissertação - Das ações preferenciais nas sociedades anonimas, ainda sem costura, por atrazo da tipografia, que os imprimira.

- Isto são horas! obtemperou Julio MaIA, em tom repreensivo, mas satisfeito, ao ve-lo entrar. Arriscou-se a perder o concurso! 
$\mathrm{E}$ as inscrições logo se encerraram, quando o relogio bateu as quatro horas da tarde.

6 Homem bom, fundamentalmente bom, mas sobretudo homem de bem, em toda a extensão do conceito, Julio MaIA se sobressaiu como funcionario digno e, acima de tudo, como secretario inegualavel e inexcedivel. Assiduo, cumpridor de seus deveres, fazia tudo, assistia a tudo. Corretissimo no trato com os professores, com os empregados, com os alunos, e com o publico, imprimiu aos serviços de sua secretaría ordem e disiplina, que nunca falharam. Todos estavam sempre a postos, a começar pelo secretario, responsavel pela administração interna da Faculdade de Direito, a que ele superintendia pessoalmente. Nas inscrições de exames, nas matriculas, o seu trabalho redobrava. Atendia a todos e examinava os requerimentos, um a um, em todos escrevendo, de seu punho, os despachos, que os diretores simplesmente assinavam. Resolvia os incidentes com tal acerto, que jamais surgiu dissidio entre ele e os diretores. De resto, era incapaz de manifestar-se sobre algum, diferente do costumeiro, sobre que não os ouvisse antes. A sua lealdade era a toda prova, sem falhas. E a sua discrição! Que alta nobreza de linhas! Contando com a estima dos professores, vivendo com eles na mais franca camaradagem, era de ve-lo, todavia, no seu posto de secretario, nas congregações! Assistente impassivel, nunca se permitiu intervir nos debates, ainda que para um simples esclarecimento, senão quando fosse determinada a sua audiencia! Disso lhe adveiu a confiança, que de todos mereceu e não desmereceu.

Justificadas foram, por isso mesmo, estas palavras do seu discurso de despedida da Faculdade de Direito:

"Diz-me a conciencia que, na repulsa de desejos desarrazoados, nenhum prejuizo causei a quem quer que fosse, nada, portanto, graças a Deus, tendo de que me penitenciar, até esta data, em materia atinente ao serviço publico. 
"Alguns dos 15 diretores, que dirigiram os destinos desta casa, a partir do Dr. Herculano de Freitas até o Dr. Waldemar Ferreira, que preside á presente sessão, inclusivé o Dr. Reynaldo Porchat, reitor da Universidade de São Paulo, e todos os atuais professores desta Faculdade, aqui fizeram o seu curso academico, ao tempo em que fui funcionario.

"Das sucessivas gerações de academicos que durante a minha aprendizagem de funcionario, perlustraram os humbrais e as salas deste mais que secular edificio, templo de ciencia e de civismo, muitos deles notaveis e cujos nomes não preciso mencionar, para me não tornar fastidioso, e são, por demais, conhecidos por todos nós brasileiros, abrilhantaram e ainda abrilhantam, no país e fóra dele, os diferentes ramos da atividade humana, desempenhando altas funções na governança e na magistratura da União e dos Estados, na diplomacia, na direção de modelares institutos de ensino superior, na politica, no parlamento, na advocacia, na medicina e na cirurgia, na engenharia, nas finanças, no jornalismo, no comercio, nas industrias e na lavoura, e de todos eles ainda conservo gratas e impereciveis recordações pela distinção, com que sempre me trataram e pela amisade, com que ainda me cativam"

Estão, ainda agora, no momento de dactilografar estas laudas, para serem impressas, a ressoar-me essas palavras, ungidas de uma leve magua: a que se apossou de Julio MAIA ao verificar que a sua aposentadoria compulsoria ia priva-lo de comemorar, no seu posto de secretario da Faculdade de Direito, cincoenta anos de grandes e inolvidaveis serviços, e a nós outros, os que o estimavamos devéras, de prestar-lhe as homenagens, a que fizera jus.

7. O primeiro dia deste ano de 1938 foi um glorioso dia de sol alto e claro. Quando, no cemiterio da Consolação, me abeirei do tumulo, que ia recolher o corpo de Julio Maia, na vespera falecido, e transportado da sua casa da rua da Abolição, onde sempre viveu, para a sua derradeira 


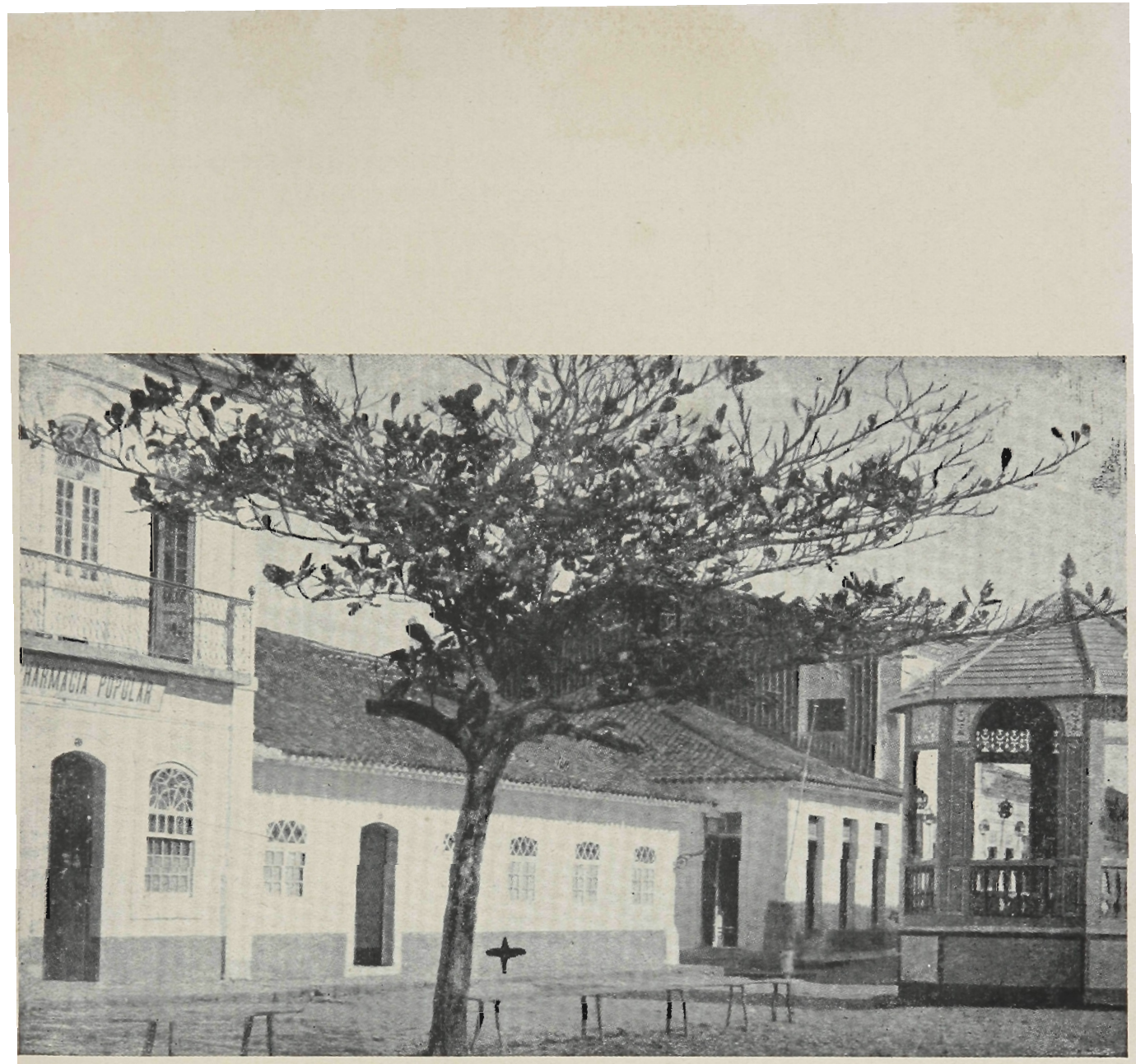

Assinalada por uma cruz, a casa, onde nasceu Julio Maia, no largo da Matriz, de Iguape. 
morada, tive os olhos humidecidos ao dizer os adeus da Congregação dos Professores ao funcionario eximio e ao companheiro de todos os momentos. Desaparecia ele coberto das bençãos de cincoenta gerações, que nele viram o homem que só praticara o bem e vivera longa e felizmente, em paz com a conciencia, firme no posto, que tanto dignificou.

0 homem bom foi sepultado no dia do ano bom!

\section{HOMENAGEM DA FACULDADE DE DIREITO DE SÃO PAULO AO DR. JULIO MAIA}

Comemorando a data aniversaria da fundação dos cursos juridicos no Brasil, a Faculdade de Direito de São Paulo, em 11 de agosto de 1920, prestou ao seu secretario, JULIO JOAQUIM GONÇALVES MAIA, homenagem tocante e sugestiva, inaugurando o seu retrato, que numa das paginas desta revista se reproduz.

Deu dela o Jornal do Comercio, edição que então se publicava em São Paulo, esta noticia:

A's 20 horas, no salão nobre da Faculdade de Direito, realizou-se a sessão solẹne em homenagem ao Secretario da Faculdade.

Entre as inumeras familias, colegas, ex-alunos da Academia, representações e academicos notámos: Primeiro Tenente Tenorio DE Brito, representando o Dr. Washington Luis, Presidente do Estado; Dr. Jaime Ferreira, Oficial de Gabinete do Sr. Secretario da Fazenda; Dr. Trto Prates, Oficial de Gabinete do Sr. Secretario da Agricultura; Capitão Marinho Sobrinho, ajưante de ordens do Sr. Secretario do Interior; José Lannes, representando o Sr. Secretario do Interior; $10^{\circ}$ Tenente Joaquim Ribeiro Dutra, representando o general Celestino Bastos, comandante da Região Militar; Francisco Amaral, representando o Sr. Delegado Geral; Dr. Benjamin Reis, Secretario da Faculdade de Medicina, representando essa Faculdade e seu respetivo Diretor Dr. Oridio P. dE Campos; Dr. Rodolpho Santiago, representando a Escola Politécnica; José M. QUIrino e Antonio Rodrigues Neto, representando o Gremio Ginasial 